\title{
CORRELATION BETWEEN COST AND PERFORMANCE OF DRINKING WATER PIPE NETWORK DURING NORMAL OPERATING CONDITIONS
}

\author{
Hanan A. Fouad ${ }^{1}$, Ahmed M. AboElmagd ${ }^{2}$, Wail A. Fahmy ${ }^{3}$, Marwa A. Diab ${ }^{4}$ \\ ${ }^{1}$ Associate Professor of Sanitary \& Environmental Engineering, Faculty of Engineering at Shoubra, Benha University, \\ 108 Shoubra St., Shoubra, 11629, Cairo, Egypt. \\ ${ }^{2}$ Assistant Professor of Sanitary \& Environmental Engineering, Faculty of Engineering at Shoubra, Benha University, \\ 108 Shoubra St., Shoubra, 11629, Cairo, Egypt. \\ ${ }^{3}$ Assistant Professor of Irrigation \& Drainage Engineering, Faculty of Engineering at Shoubra, Benha University, 108 \\ Shoubra St., Shoubra, 11629, Cairo, Egypt. \\ ${ }^{4}$ Demonstrator of Sanitary \& Environmental Engineering, Faculty of Engineering at Shoubra, Benha University, 108 \\ Shoubra St., Shoubra, 11629, Cairo, Egypt.
}

\begin{abstract}
Now a days, large expenditures are spent on maintenance and rehabilitation of water distribution systems due to lack of performance. This research work is concerned with investigating the relationship between the cost of a certain water distribution network design and its performance during normal operating conditions. Noting that performance is expressed by an efficiency index. By analyzing eighteen alternative designs of a particular networks, it has been concluded that the efficiency of water delivery is inversely proportional to the cost of a water distribution system with a strong coefficient of determination. Also, increasing the number of pipes in a network would result in more leakage problems and subsequently lower efficiency. Finally, the proposed equation that describes the cost-efficiency relationship can be effectively utilized to determine the cost of a design with desirable efficiency or the efficiency corresponding to a known cost.
\end{abstract}

Keywords: Water Distribution Network; Performance Evaluation; Efficiency; Cost of Water Networks; Efficiency; Normal Operation Conditions.

\section{INTRODUCTION}

Water distribution Networks (WDNs) play an essential role in our modern society and its productivity. These crucial complex systems consists of miles of pipes buried under ground, several pumps, valves, and storage reservoirs with the main purpose of effectively conveying safe water from storage plants to customers' taps, and in the same time, satisfying all main routine consumptions and emergency requirements (Mays, 1999). However, nowadays, large expenditures are spent on maintenance and rehabilitation of WDNs due to lack of performance. Low performance, also, causes environmental issues as a result of exhausting more power and resources while heavily burdening the environment with huge quantities of waste produced (Jalal, 2009).

This paper is associated with studying the relation between the cost and performance of water distribution networks during normal functioning conditions, in which, a WDNshould be capable of satisfying all functional requirements (consumption demands) with adequate pressures and without interruptions. The study is performed by analyzing eighteen alternative designs of a certain distribution network. In the following sections, calculating the performance of networks, description of the various designs along with the output results are discussed.

\section{PERFORMANCE OF WDNS DURING NORMAL OPERATING CONDITIONS}

Performance evaluation can be defined as "any approach that permits for the valuation of the competence or the effectiveness of an operation or activity out of the creation of performance measures" (Alegre and Coelho, 2012) where a performance measureis defined by performance indicatorsthat is a "quantitative measure of a certain aspect of the water undertaking's performance orstandard of service" (Quadros et al., 2010). In this study, the used indicator to express the performance of a distribution network is the efficiency index, discussed in the following section.

\subsection{Efficiency Index (eff)}

Water leakage is usually the main reason for water loss in WDNs.In some countries, water loss due to leakage in the supply network overruns $40 \%$ of the water supplied (see Figure 1). 


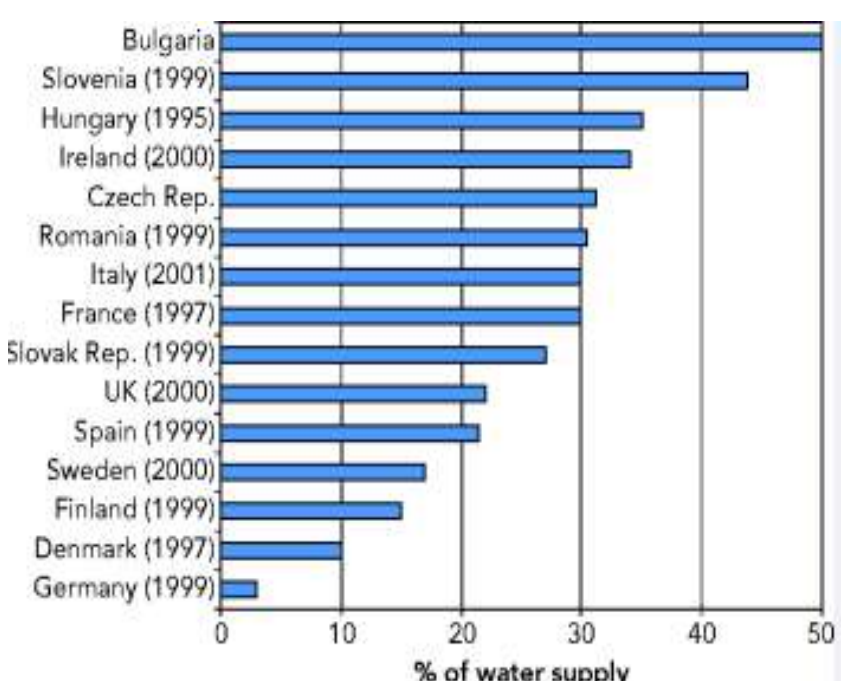

Fig. 1: Leakage from urban water systems (EEA, 2008).

Moreover, it has been estimated that about 32 billion cubic meters of water are to be lost each year from distribution systems because of leakage (Liemberger and McKenzie, 2006). Additionally, Burn et al. (1999) stated that the global value of these losses is of the order of $\$ 81$ billion annually.

Waste of water due to leakage is governed by many factors including but not limited to material characteristics of pipes, hydraulic features of the surrounding soil, shape and hydraulics of the leak opening, corrosion, and water hammer and excessive loads. However, the governing factor remains the available pressure in WDN.

Twort and Hoather (1974) reported that the available pressure inside the networks caused around $5-55 \%$ of total supply loss in the form of leakage from different parts of a WDN. In addition, water supply needs intense energy demand, reported as $2 \%-3 \%$ of the worldwide power (Zaragoza, 2007). Thus, water leakage causes the waste of significant amount of water and power, and as a result, money. Therefore, leakage is a real crucial factor and is consideredto govern the performance rate of a distribution system during. Furthermore, it has examined during normal operating state because in this case, the maximum possible leak occurs due to the existence of maximum available pressure.

In the literature, a number of relations have been proposed to estimate the leakage losses based on the pressure head in pipes (e.g. in Vela et al., 1991 and Tabesh et al., 2009). One of the most commonly used relation is Germanopoulos technique because of its simplicity and it is employed in this study such that the amount of leaked water from a pipe $\left(Q_{p}^{\text {leak }}\right)$ is (Germanopoulos, 1985):

$Q_{p}^{\text {leak }}=C L_{p}\left(P_{P}^{\text {ave }}\right)^{1.18}$

where $L_{p}$ is the pipe's length (m) and $P p{ }^{a v e}$ is the average residual pressure in the pipe $(\mathrm{m})$,computed by averaging the pressures at the pipe's start and end nodes. The subscript " $p$ " stands for the pipe number. $C$ is a constant depending on pipe properties (e.g. material, age, and leakage points per unit pipe length. Here, $C$ is used as 0.0001 (Gheisi andNaser, 2015). The Efficiency Index (eff) is used to express the performance considering wasted water due to leakage. It determines the percentage of actual supplied water to customers with respect to the supplied water plus the leaked water from the pipes(Bertola and Nicolini, 2006).

$e f f=\frac{\sum_{n=1}^{N} Q_{n}^{\text {sup }}}{\sum_{n=1}^{N} Q_{n}^{\text {sup }}+\sum_{p=1}^{P} Q_{p}^{\text {leak }}}$

where $Q n^{\text {sup }}$ is the supplied nodal water discharge (L/s), $n$ is the node number, and $N$ and $P$ refer tothe total number of nodes and pipes in a network, respectively.

\section{DESCRIPTION OF THE NETWORK DESIGN}

\section{ALTERNATIVES}

To determine the relationship between the cost of a network and its performance "efficiency", analysis is performed on 18 alternative designs of a hypothetical water distribution network. In this section, the various designs of the system are introduced. The various networks were originally designed by (Tanyimboh and Templeman, 2000) to satisfy the required demands shown in Figure2. The source pressure head at node 1 is $100 \mathrm{~m}$ and the minimum required head at all remaining nodes is $30 \mathrm{~m}$. All pipes are one-kilometer long with a Hazen-Williams coefficient of 130. Figure 3 shows each network along with its pipes' diameters and nodal pressures. Moreover, Table 1 gives the cost of each design as calculated by Tanyimboh and Templeman (2000).

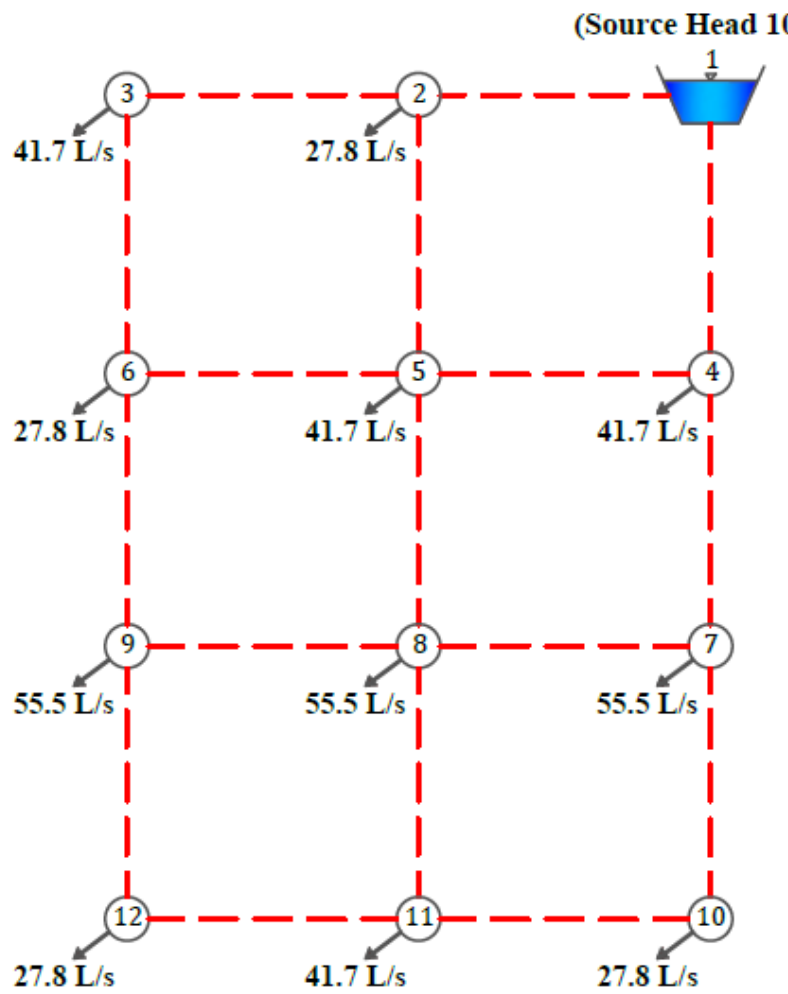

Fig. 2: Required demands at each node(Tanyimboh and Templeman, 2000). 


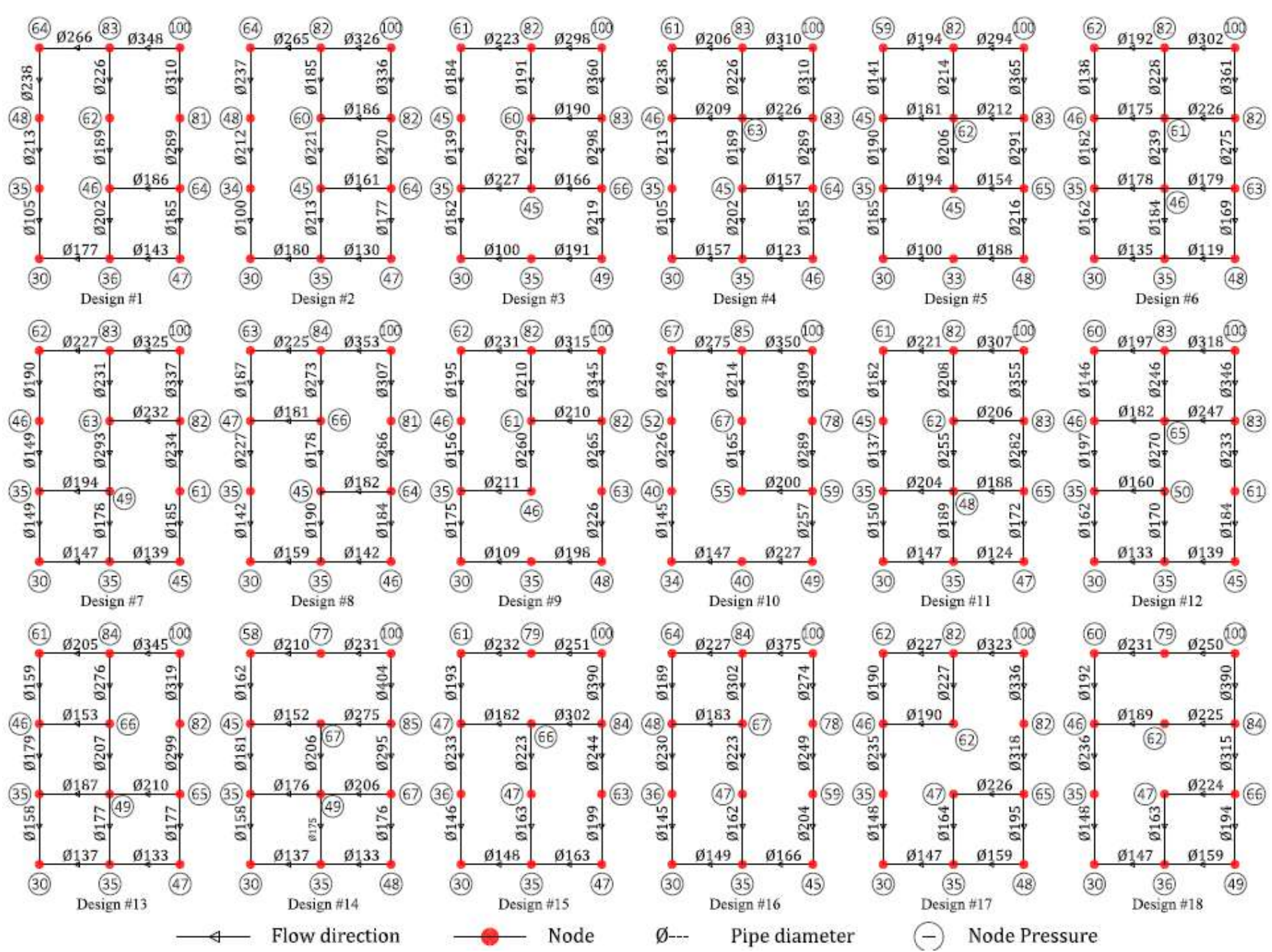

Fig. 3: The alternative designs of a WDN.

Table 1: Cost of alternative designs

\begin{tabular}{|l|l|l|l|}
\hline $\begin{array}{l}\text { Design } \\
\text { No. }\end{array}$ & $\begin{array}{l}\text { Cost } \\
\left(* £ 10^{\wedge} 6\right)\end{array}$ & $\begin{array}{l}\text { Design } \\
\text { No. }\end{array}$ & $\begin{array}{l}\text { Cost } \\
\left(* £ 10^{\wedge} 6\right)\end{array}$ \\
\hline 1 & 1.1892 & 11 & 1.2527 \\
\hline 2 & 1.2201 & 12 & 1.2531 \\
\hline 3 & 1.2195 & 13 & 1.2468 \\
\hline 4 & 1.2591 & 14 & 1.2318 \\
\hline 5 & 1.2514 & 15 & 1.4099 \\
\hline 6 & 1.2814 & 16 & 1.3069 \\
\hline 7 & 1.2232 & 17 & 1.1842 \\
\hline 8 & 1.2243 & 18 & 1.1883 \\
\hline 9 & 1.2009 & 19 & 1.1917 \\
\hline 10 & 1.2119 & 20 & 1.1816 \\
\hline
\end{tabular}

\section{RELATIONSHIP BETWEEN COST AND}

\section{EFFICIENCY}

\subsection{Calculation of the Efficiency Index (eff)}

In this research work, the hydraulic analysis of the water distribution system is conducted using Bentley WaterGEMS
V8i software (Bentley, 2006). The efficiency index is calculated in case that pressures are sufficient to deliver the required demands to all parts of the system. The achieved pressures were computed from the hydraulic analysis. The nodal pressures are used to determine the pressures inside the network pipes where the pipe pressure is the average of pressures at its start and end nodes. The leakage through pipes is calculated by Germanopoulos method (Equation 1).

To illustrate how effis calculated, Table 2 lists the results of hydraulic analysis for Design \#1 (nodal pressures, pressure in pipes, and the amount of leaked water from each pipe). The total amount of leaked water in Design \#1 during normal operating conditions is the sum of values in column 7 in Table 2 which equals $170.1552 \mathrm{~L} / \mathrm{sec}$ and the supplied water is the sum of network demands shown in Figure 2 (444.5 L/sec). By applying Equation 2, eff $=444.5 /$ $(444.5+170.1552)=0.7232$. Similarly, the efficiency index is determined for other designs. Table 3 indicates the efficiency for all networks 
Table 2: Nodal pressures, pressure in pipes, and the amount of leaked water (Design \#1).

\begin{tabular}{|l|l|l|l|l|l|l|}
\hline $\begin{array}{l}\text { Node } \\
\text { number }\end{array}$ & $\begin{array}{l}\text { Nodal pressure } \\
\left(\mathrm{m} \mathrm{H}_{2} \mathrm{O}\right)\end{array}$ & $\begin{array}{l}\text { Pipe } \\
\text { Number }\end{array}$ & $\begin{array}{l}\text { Start node } \\
\text { pressure }\end{array}$ & $\begin{array}{l}\text { end } \\
\text { node pressure }\end{array}$ & $\begin{array}{l}\text { Pressure inside } \\
\text { Pipe }\left(\mathrm{m} \mathrm{H}_{2} \mathrm{O}\right)\end{array}$ & $\begin{array}{l}\text { Leakage from } \\
\text { pipe }(\mathrm{L} / \mathrm{s})\end{array}$ \\
\hline 1 & 100 & 1,2 & 100 & 83 & 91.5 & 20.62894 \\
\hline 2 & 83 & 1,4 & 100 & 81 & 90.5 & 20.36317 \\
\hline 3 & 64 & 2,3 & 83 & 64 & 73.5 & 15.93012 \\
\hline 4 & 81 & 2,5 & 83 & 62 & 72.5 & 15.67469 \\
\hline 5 & 62 & 3,6 & 64 & 48 & 56 & 11.55745 \\
\hline 6 & 48 & 4,7 & 81 & 64 & 72.5 & 15.67469 \\
\hline 7 & 64 & 5,8 & 62 & 46 & 54 & 11.07196 \\
\hline 8 & 46 & 6,9 & 48 & 35 & 41.5 & 8.115154 \\
\hline 9 & 35 & 7,10 & 64 & 47 & 55.5 & 11.43578 \\
\hline 10 & 47 & 7,8 & 64 & 46 & 55 & 11.31431 \\
\hline 11 & 36 & 8,11 & 46 & 36 & 41 & 7.999907 \\
\hline 12 & 30 & 9,12 & 35 & 30 & 32.5 & 6.081663 \\
\hline & & 10,11 & 47 & 36 & 41.5 & 8.115154 \\
\hline & & 11,12 & 36 & 30 & 33 & 6.192221 \\
\hline
\end{tabular}

Table 3: Efficiency of water delivery ofall designs

\begin{tabular}{|l|l|l|l|}
\hline Design No. & Efficiency & Design No. & Efficiency \\
\hline 1 & 0.723170 & 11 & 0.696850 \\
2 & 0.707350 & 12 & 0.696302 \\
3 & 0.706927 & 13 & 0.698924 \\
4 & 0.694242 & 14 & 0.699635 \\
5 & 0.695700 & 15 & 0.713953 \\
6 & 0.684400 & 16 & 0.733597 \\
7 & 0.710136 & 17 & 0.723026 \\
8 & 0.709724 & 18 & 0.723312 \\
9 & 0.720350 & 19 & 0.723870 \\
10 & 0.724667 & 20 & 0.723335 \\
\hline
\end{tabular}

\subsection{Relationship between Cost and Efficiency}

Trying to figure out how could the cost of a certain design influence the value of efficiencyi.e. the performance level of the network, Figure 4 plots the relation between the both factors for the eighteen design.

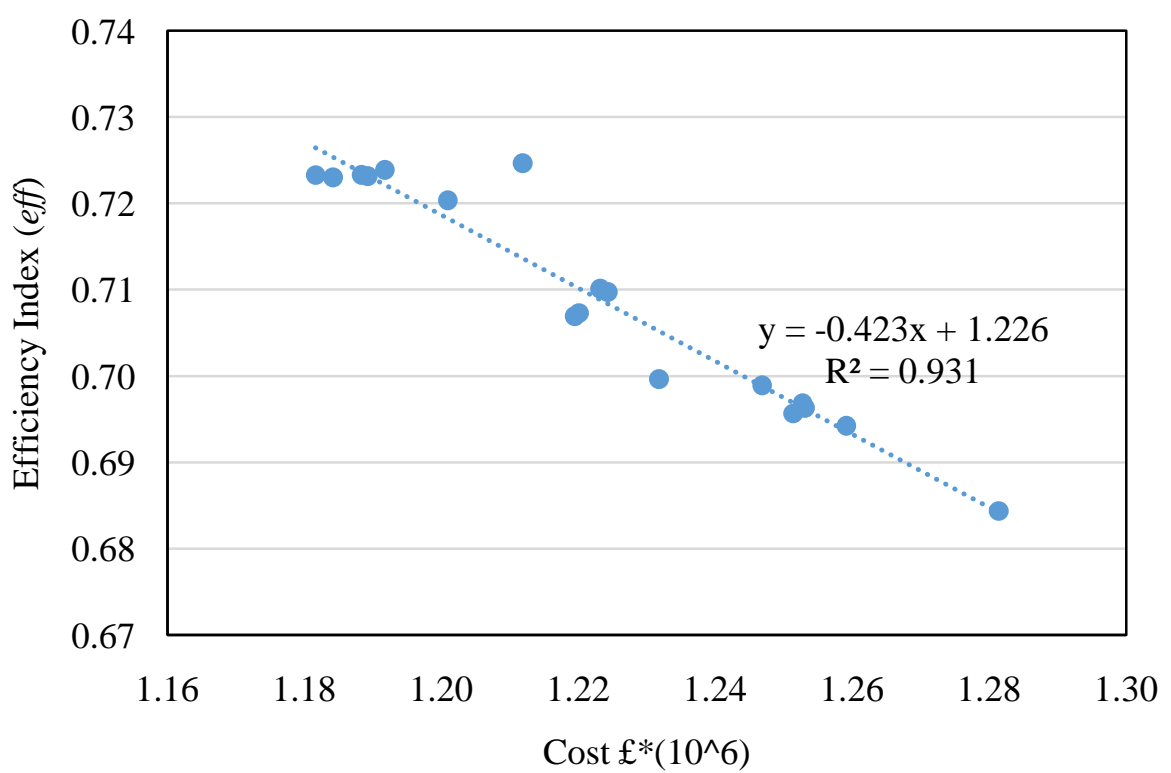

Fig. 4: Correlation between cost and eff. 
It is obvious that there is a strong negative correlation between the cost and efficiency of water delivery. This elucidates that high cost does not necessarily mean high performance. However, trying to describing the cause of this inverse relation, the effect of the number of pipes in each design and the efficiency is displayed in Figure 5.

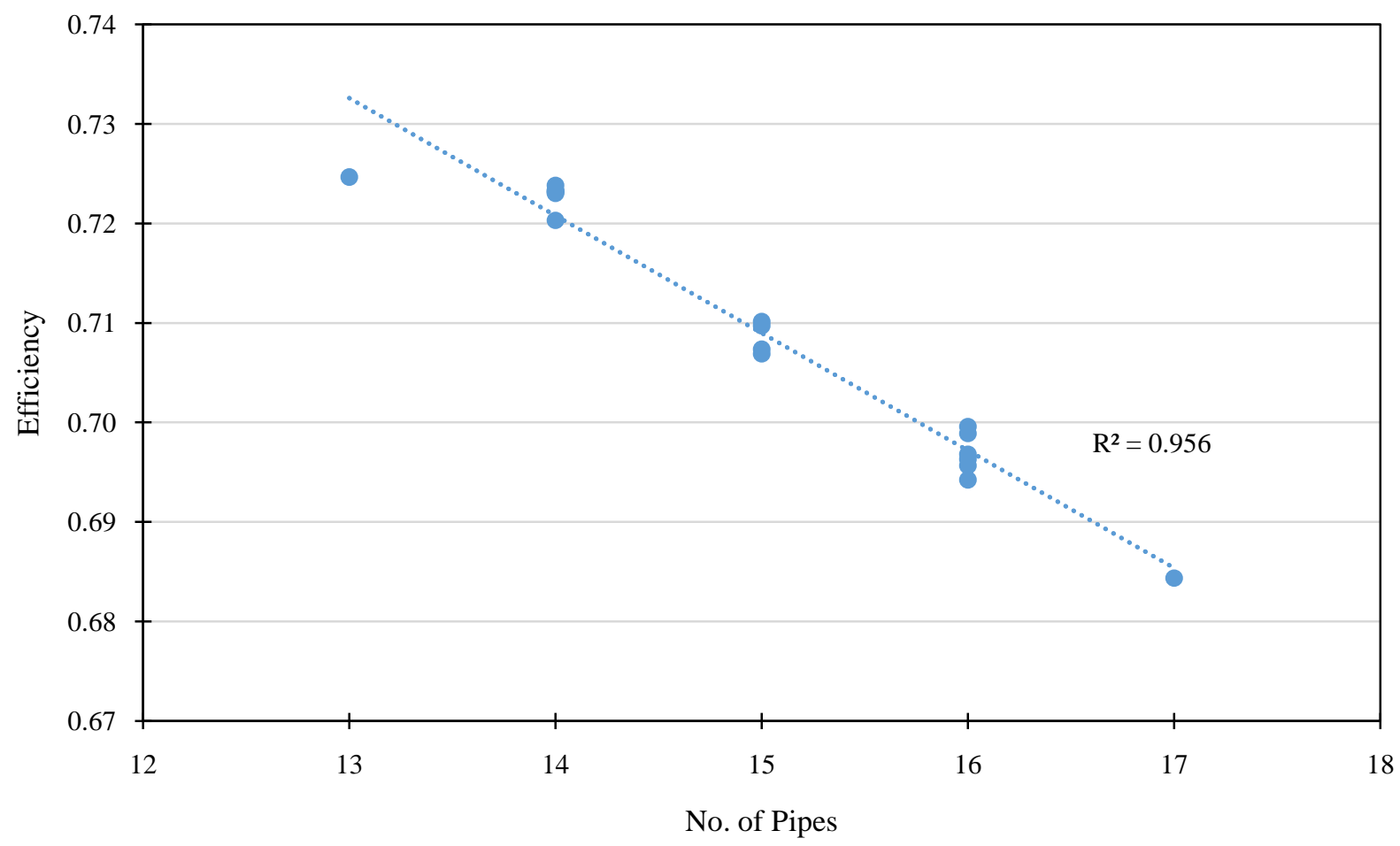

Fig. 5: Relationship between number of pipes and efficiency.

The cost mainly depends on the number of pipes. And, it has been found that increasing the number of pipes results in lower efficiency. This is because more pipes mean more leakage. In the same time, eff has a negative relation with the number of pipes (Figure 5). This explains the resulting relation in Figure 4. In general, this equation (eff $=1.2264$ $0.4231 * \operatorname{cost})$ can be effectively utilized to determine the cost of a design with desirable efficiency or the efficiency corresponding to a known cost.

\section{CONCLUSION}

Based on the previous discussion, the following points are concluded:

- The efficiency of water delivery is inversely proportional to the cost of a water distribution system with a strong $R^{2}$.

- Increasing the number of pipes in a network would result in more leakage problems and subsequently lower efficiency.

- As the number of pipes increase, the cost of design increases.

- The proposed equation that describes the cost-efficiency relationship can be effectively utilized to determine the cost of a design with desirable efficiency or the efficiency corresponding to a known cost.

\section{REFERENCES}

[1] Alegre, H., \& Coelho, S. T. (2012). Infrastructure asset management of urban water systems, pp. 49-73. INTECH Open Access Publisher.

[2] Bentley Systems (2006). WaterGEMS, Bentley Systems Incorporated, Exton, PA.

[3] Burn, S., DiSilva, D., Eiswirth, M., Hunaidi, O., Speers, A., Thornton, J. (1999). "Pipe LeakageFuture Challenges and Solutions." Pipes Wagga Wagga, Australia.

[4] EEA. European Environment Agency (2008). Available from: http://www.eea.europa.eu/ legal/copyright.

[5] Gheisi, A., \& Naser, G. (2015). Multi-aspect Performance Analysis of Water Distribution Systems Under Pipe Failure. Procedia Engineering, 119, pp. 158-167.

[6] Jalal, M. M. (2009). Performance Measurement of Water Distribution Systems (WDS): A critical and constructive appraisal of the state-of-the-art(Doctoral dissertation).

[7] Liemberger, R. and McKenzie, R. (2006). “Accuracy Limitations of the ILI - Is it an Appropriate Indicator for Developing Countries?" AESBE, pp.1-8.

[8] Mays, L. W. (1999). Water distribution system handbook. New York,USA: McGraw-Hill Professional Publishing.

[9] Bertola, P., Nicolini, R. (2006). Evaluation reliability and efficiency of water distribution networks, In 
Proceedings of the conference efficient management of water networks design and rehabilitation techniques, Ferrara.

[10] Quadros, S., Rosa, M. J., Alegre, H., \& Silva, C. (2010). A performance indicators system for urban wastewater treatment plants. Water Science and Technology, 62(10), pp. 2398-2407.

[11] Tabesh, M., Soltani, J., Farmani, R., \& Savic, D. (2009). Assessing pipe failure rate and mechanical reliability of water distribution networks using datadriven modeling. Journal of Hydro informatics, 11(1), pp. 1-17.

[12] Tanyimboh, T. T., \& Templeman, A. B. (2000). A quantified assessment of the relationship between the reliability and entropy of water distribution systems. Engineering Optimization, 33(2), pp. 179-199.

[13] Twort, A. C., Hoather, R. C., \& Low, F. M. (1974). Water supply, $3^{\text {rd }}$ Ed. Edward Arnold Ltd. Pub., London.

[14] Vela, A., Perez, R., \& Espert, V. (1991). Incorporation of leakages in the mathematical model of a water distribution network. In The $2^{\text {nd }}$ International Conference on Computer Methods in Water Resources, Marrakesh, Morocco, pp. 245-257.

[15] Zaragoza, G., Buchholz, M., Jochum, P., \& PérezParra, J. (2007). Watergy project: Towards a rational use of water in greenhouse agriculture and sustainable architecture. Desalination, 211(1), pp. 296-303. 